\title{
9. From collaboration to coercion: a story of governance failure, success and opportunity in Australian Indigenous affairs
}

\section{Diane Smith}

\section{The West Arnhem Shire: a story of governance success}

In late June 2007, I was at the South Alligator River in Kakadu National Park attending a meeting of Indigenous leaders from local government councils and resource organisations representing communities throughout West Arnhem Land and the town of Jabiru in the Northern Territory (NT). They were meeting, as they had done regularly for the past three years, to plan the implementation of a local government shire covering the entire region of West Arnhem and Jabiru. Also present were senior officers from the NT and Federal Governments, who, under a bilateral agreement signed between the two governments in 2005 , have been working closely with the Indigenous leaders on the transitional committee to facilitate the establishment of effective and culturally legitimate regionalised local government. ${ }^{l}$

In 2003, Aboriginal (Bininj) leaders from West Arnhem Land saw the NT Government regionalisation policy as an opportunity to secure greater authority and control for Bininj people over the things that mattered to them, and to create a strong voice that could influence government funding and service delivery to the region: 'We will get to say what we want in our communities, we will set the priorities'; 'We have control over this project'; 'We will create policies and strategies that achieve more local employment and better services'; 'We will have a much stronger voice speaking as one to government'.

Part and parcel of the regionalisation process has been the regular delivery, as an integral part of each committee meeting, of governance capacity development with the Indigenous and non-Indigenous members of the committee. This has been carried out by the same team of community-development officers from the NT Department of Local Government, with my research support, for more than three years (see Evans et al. 2006; Smith 2005, 2007). The governance work included sessions on governing roles and responsibilities, separation of powers, systems of representation, organisational structures, codes of conduct and conflict of interest, meeting procedures, human-resource management and contract conditions, and so on. Each session culminates in the committee collectively 
developing new governing rules - for example, in the form of written policies, agreed procedures, resolutions and a future constitution and preamble.

An important driving force behind these efforts has been the desire to create an effective regional organisation that will better reflect Bininj cultural values and institutions: 'We will have a council that respects and works with our culture.' As part of the governance capacity-building work, the Indigenous committee members routinely discuss the cultural issues involved in developing workable rules; they test proposed policies against potential community and cultural scenarios, and share practical ideas with government officers about how they might collectively and individually enforce their rules in a way that acknowledges the difficult challenges involved in working across cultures.

The result is that the community leaders on the committee have developed strong governing capacity and confidence based on the experience of working together as a team to make and enforce collective decisions. They follow up difficult issues of representation and externally imposed change with tenacity and integrity, and their relationship with the NT and Federal Government partners continues to be frank and robust.

\section{Collaborating for good governance}

Figure 9.1 Logo design for the proposed West Arnhem Shire, as endorsed by the Shire Transitional Committee, 2007.

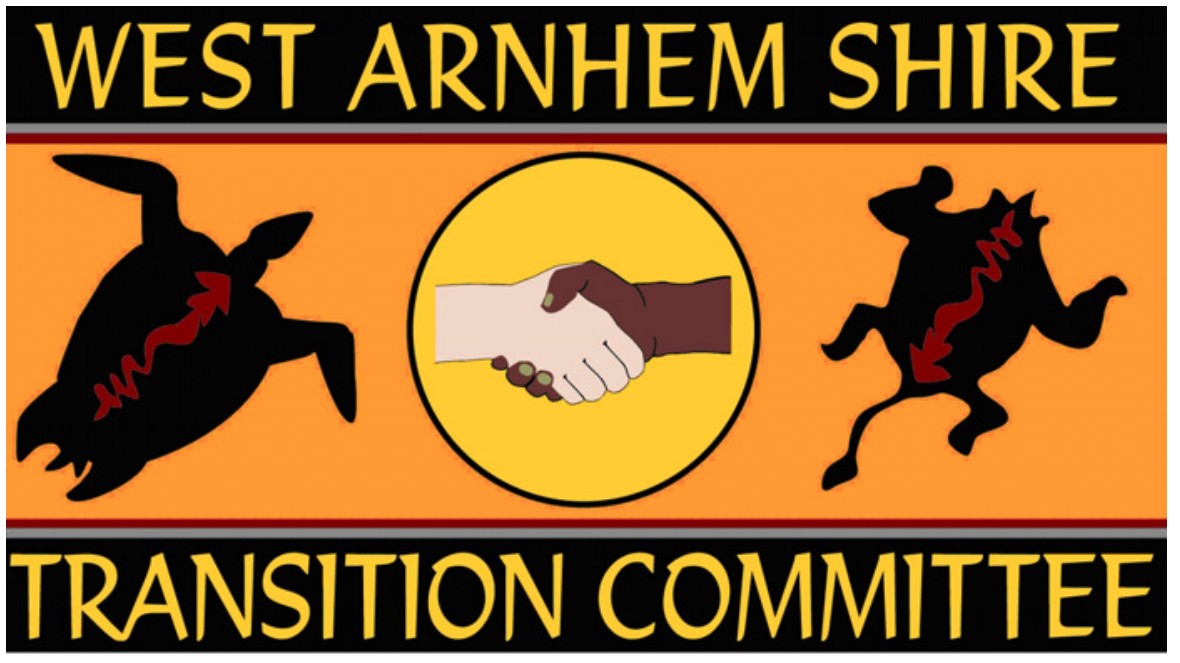

Note: The logo for the shire was designed by Ahmat Brahim, an Indigenous man with traditional ties to the region, whose father was a member of the Transitional Committee.

The West Arnhem Shire logo endorsed by the committee demonstrates their real commitment to working as a 'joined-up' local government with the other levels of government in Australia for the benefit of Bininj and Balanda (non-Aboriginal) 
residents of the region. Their intention, written into their early constitution preamble and policies, is to use their traditional systems of culture and governance

to strengthen the legitimacy of the Regional Authority [shire], and use the [shire] to strengthen traditional systems of governance. Through this vision and commitment we seek to maintain observance and respect for traditional values, and to join the responsibilities and structures of traditional authority with those of local government, to achieve a high quality of life and a wide range of opportunities and choices.

We are developing our own rules that include our culture. In our own culture we have our own rules that are very strong and we are bringing this into the [regional local government].

The collaboration between Bininj groups across the region, and with government, hasn't all been smooth sailing by any means. The history of mutual suspicion is slowly shifting as a result of the trust and relationships being built up between the government community-development officers, community leaders and different clan groups, and as the committee members work with one another to resolve practical issues and develop shared approaches.

As one member of the committee noted in a presentation to NT Government ministers in 2005:

When we started, people were unsure of each other. People were only interested in their own group. We had our own ideas - at the beginning we were all different. We were not used to making decisions together. Now, people have a shared commitment to the whole region. We are all working towards the one goal. Now we work through issues and make an agreed decision.

Major changes initiated in 2006 by the NT Government to its policy framework for local government have severely tested the partnership relationship. The foundation of governance capacity, however, trusted relationships with particular government officers and the growing effectiveness of Bininj decision making within the committee have built resilience in the committee and the partnership. Also, the Bininj leaders remain strongly committed to achieving real outcomes on the ground. For that purpose they continue to collaborate with government to create workable solutions that will address the entrenched backlogs in infrastructure and essential services in the region.

\section{West Arnhem: from collaboration to coercion}

On the final day of the West Arnhem Shire committee meeting in late June 2007, the Federal Government issued a media release announcing that it was taking over the administration of some $60 \mathrm{NT}$ Aboriginal communities, under 
compulsory lease acquisition, for an estimated period of five years. The release stated that government administrators, the Army and police would be placed into each community and children would be required to undertake mandatory health checks in an effort to identify and curb child abuse. All communities located on Aboriginal inalienable freehold land under the Aboriginal Land Rights Act (NT) 1976 would have their permit systems revoked and be subject to Australian Government leasehold conditions.

Government officers at the West Arnhem meeting were unable to shed any light on the media announcement - they had not been forewarned themselves and had to resort to the media release. Quick calls to their managers in Darwin and Canberra revealed that they were similarly uninformed.

The next day, the front-page headline of the NT News read 'Martial Law - Howard mobilises cops, military as he declares "national emergency" in NT communities'. The opening paragraph reported:

The Federal Government yesterday seized control of the Territory's Aboriginal communities in the most dramatic intervention in NT affairs since self-government. Canberra in effect declared martial law over the 44 per cent of the Territory owned by Indigenous people. (Adlam and Gartrell 2007)

To say that the Bininj members of the West Arnhem committee were shell-shocked would be an understatement. In one day, without any consultation, their collaboration with the Federal Government had essentially been made null and void. Their role as the proposed local government for the entire region was thrown into question, their work in the past three years ignored and their governance roles treated with disdain. A week after the media release, the Army, police and Federal Government officials entered two communities in the region.

The West Arnhem group of Indigenous leaders had been working in partnership with the NT and Federal Governments for more than three years. Their sense of betrayal was intense, but not new. It took me back several years to 2001 when I worked with the Mutitjulu community at their request to develop a welfare-reform package for the whole community.

\section{Mutitjulu: a litany of broken promises}

In 1991, the Ngaanyatjarra, Pitjantjatjara Yankunytjatjara (NPY) Women's Council reported to government on the welfare of Indigenous (Anangu) children and families in the central Australian region that included the Mutitjulu community. The Aboriginal chairwoman of the council stated in her introduction to the report:

We are telling this story strong about what we think about child protection...Women's law, grandmothers' law is really important one 
to us...It teaches us [the] right way for children to be looked after and taught.

But a lot has changed for us on our communities. We are worried about losing our traditional means of controlling and caring for children. We are worried about our family structure breaking down. We are worried about grog and petrol sniffing and how that affects our families. And we are also worried that government and welfare mob don't understand our way and our problems.

We women have ideas about what to do to make it better. We want government and welfare mob to listen to what we say and our ideas. We want them to work with us and our organisations to get it right. (R. Forbes, NYP Women's Council, 1991)

Ten years later, after years of further inquiries and reports into their family living conditions - and little to show for it except band-aid responses from governments - the Anangu families and leaders of the Mutitjulu community had had enough.

In response to the national welfare-reform agenda of the Federal Government in 2000, the community council at Mutitjulu asked Centrelink, the Aborginal and Torres Strait Islander Commission (ATSIC) and Families and Community Services (FACS) to work with them to develop a practical strategy to address welfare dependence and related family problems in the community. Under a joint contract between ATSIC and the community council, I lived and worked in the community to ascertain what Anangu considered to be their priority welfare problems and their ideas for resolving them. In that time, I consulted with senior leaders and family members, young and old, all community organisations and service deliverers, as well as regional stakeholders and relevant government agencies (see Smith 2001).

Not surprisingly, Anangu concerns had changed little since 1991:

'Sit-down money' is killing our young people.

When the welfare money came in, it really killed the work; people started slacking off. Now young ones don't know work, they're welfare trained.

No more sit-down money, we gotta cut it out. Level 'm up, everyone gotta work.

Push all those petrol sniffers into work. Young people make everything good for family. I like them to be helping more with all the community work.

Out of the consultation process, the Mutitjulu Community Council and senior family leaders proposed a Community Participation and Partnership Agreement to be negotiated with the relevant Federal Government departments and key 
regional stakeholders. In 2001, it was a unique, innovative model; it came well before the Council of Australian Government (COAG) trials and before the Family Income Management pilot projects in Cape York.

The Mutitjulu Community Participation and Partnership Agreement proposed an integrated package aimed at directly attacking welfare dependence and social dysfunction in its real-life community context. Key components included the following.

- Community-wide coverage of all welfare recipients - what Anangu called the 'all-in' approach — with breaching implemented in partnership with Centrelink.

- A whole-of-community participation program based on Individual Participation Agreements that would require all welfare recipients to undertake some form of work selected from a menu of participation activities and training developed by the community.

- Tying receipt of Youth Allowance to school attendance and work participation.

- Providing intensive assistance and support to individuals to take up paid employment.

- Recognising the support role and social capital provided to families and children by older women, and creating mechanisms to ensure that welfare payments intended for the care of children were directed to the older women who invariably took care of them.

- Government agencies working alongside the community to rebuild local governance processes and provide governance capacity building to Anangu leaders and councillors to enable them to actively participate in, and manage, the implementation process.

The Mutitjulu Council proposed that the agreement should be further fleshed out and implemented in partnership with the Federal Government, FACS, Centrelink and ATSIC. Accordingly, it asked the government to:

- provide a delegation to a community officer under the Social Security Act 1999 to enable the council (or other specific-purpose community organisations) to implement a whole-of-community approach to welfare reform

- support them in developing local Anangu breaching and enforcement rules and appeals procedures with Centrelink

- provide a consolidated block of welfare and related program funding, with a single reporting/acquittal package - what Anangu referred to as a 'one-bucket' funding strategy

- provide families with financial literacy and budgeting training, and with local banking services. 
The community was not naive about the challenges for its side. Residents were adamant that they wanted a measured transition carried out in partnership with government, with sustained departmental facilitation on the ground.

Senior officers from the Federal Government visited the community and attended council meetings at which they assured local leaders that the government was listening to their proposal and would support them. That was the last the community heard of them.

What happened? Essentially, in 2001, the Federal Government and its departments walked away from Mutitjulu. Initially, the government departments involved argued that there needed to be further community consultation, and suggested that the community was in fact 'too dysfunctional' to participate in such a major reform process. (In fact, continuing consultation was an integral part of the proposed implementation process.)

In reality, the problem lay not in the community, but in Canberra. First, the key departments would not support an 'all-in' community model of welfare reform and would not support linking Youth Allowance with school attendance- even though these had been specifically requested by community members and their council. Second, Centrelink and FACS would not countenance an Indigenous community working with them to develop and implement locally relevant breaching rules. They also would not countenance a community organisation being provided with a delegation under the Social Security Act in order to do so ('Over my dead body,' declared one senior bureaucrat).

Third, entrenched interdepartmental turf wars in Canberra meant that the departments concerned were unable to negotiate a common position. As a result, the process inevitably became bogged down by strategic bureaucratic behaviour that led to inertia. Finally, the Federal Government was unable or unwilling to reform the chaotic state of its departmental program funding in order to streamline the pooled funding and grant-reporting arrangements that would have been required.

In 2001, the Mutitjulu community had called out in desperation to the Federal Government. It wanted decisive action, but it also wanted to be a full partner in action to address local welfare dependence and governance dysfunction. At that point, the government turned its back on the community.

As a result, it is arguable that significant responsibility for the horror of violence, abuse and despair that has since escalated at Mutitjulu can be laid fairly and squarely at the door of the Federal Government and its departments and, in more recent years, at the door of the NT Government as well.

In late June 2007, the Federal Government announced that Mutitjulu would be the first community into which it activated national emergency measures. It would do so unilaterally, not in collaboration. Ministers and some media 
commentators have argued that, late though it is, at least action is now being taken at Mutitjulu. Two critical elements of the community's earlier partnership proposal for welfare reform are, however, noticeably absent-namely, the implementation of a governance-building strategy right from the start, and the streamlining of related government program funding down to the community.

\section{The new intervention policy}

Clearly, we are at a watershed in terms of where the Federal Government is taking Indigenous affairs policy and practice. No-one would deny the depth of problems experienced by Indigenous families and communities in this country; Indigenous people themselves have been calling for decisive action on a whole range of social, economic and human rights issues for several decades now. After years of government failure to address deeply entrenched structural disadvantage, however, should we think that the outcomes of this hasty intervention will be any better?

The new policy approach will attempt substantial social engineering within Indigenous communities. The Federal Government appears to be undertaking another missionary phase in Indigenous affairs, one based on a well-intended desire to improve conditions for families and children, but unilaterally imposed by government using 'the full weight of its coercive power' (Scott 1998:5). The history of Indigenous affairs in Australia shows that coercion rarely leads to sustained positive outcomes. On the contrary, often it has led to unintended consequences that have exacerbated problems and created profound misery on the ground.

Since the announcement of the 'Howard-Brough-Pearson' new intervention policy, we have heard a barrage of opinion - much of it partisan and ideologically driven, with many bold assertions uninformed by empirical evidence. My concern here is not with the causal grounds for the Federal Government's action in the welfare arena, but with its logic and strategies for addressing the issues, predicated as they appear to be on a lack of analysis of why government policy has failed so badly to date, and on unproven assertions of a direct connection between the Aboriginal Land Rights Act permit system and child abuse. Unless these underlying issues are addressed, there is a real chance that the current intervention will simply repeat the debilitating mistakes of the past.

Implicit in the Federal Government's new intervention approach is an acknowledgment that its current whole-of-government policy has failed, even though that policy has been implemented only recently. Is this the case, and, if so, in what respects has it failed? Also, have there been any positive outcomes from that approach?

In 2002-03, COAG trials began operating in eight Indigenous sites across Australia, in a whole-of-government, partnership policy framework and with 
an overarching emphasis on shared responsibility. The aim of the trials was twofold: first, to build Indigenous community capacity to more effectively deliver services; and second, to strengthen the capacity of governments to work with each other in a coordinated way and deliver more streamlined funding to Indigenous communities. Important lessons for governments and communities can, and should, be derived from that practical experience. In a matter of one week, however, we seemed to go from a whole-of-government policy approach to one of coercion, in which the power of the State enforced collaboration.

To develop a more empirically informed consideration of these urgent matters, I want to describe some of the relevant research findings from a major project I have been involved with in the past four years.

\section{The Indigenous Community Governance Project}

The Indigenous Community Governance (ICG) Project is itself an innovative partnership between the Centre for Aboriginal Economic Policy Research (CAEPR) at The Australian National University and Reconciliation Australia. It is being carried out in collaboration with 11 Indigenous communities across Australia, with funding from the Australian Research Council and the Federal, NT and West Australian (WA) Governments.

The research is national in coverage and community focused. It covers a range of different types of 'communities' in remote, rural and urban locations. A team of multidisciplinary researchers has been working with the same community organisations, groups and leaders for the past three years.

The project is investigating the complex dimensions of how communities are governed - not only their cultural foundations and complex histories, but the financial, legislative and policy frameworks under which they operate- and how these impact on their effectiveness and legitimacy.

The methodology is rigorous and our research results are documented extensively on the CAEPR web site (see Hunt and Smith 2006, 2007; Smith 2005). Each researcher investigates the unique aspects of governance in the communities they are working with, and also provides extensive research data against a common project field manual that targets key governance issues and questions. The project has developed an innovative comparative analysis to identify more broadly relevant principles and common themes that appear to underlie Indigenous governance challenges and solutions across the communities.

The project is participatory and applied. Researchers work with community groups and organisations to explore best-practice solutions to their governance challenges. To assist that approach, the project is also currently working with Reconciliation Australia to develop a web-based tool kit of governance resources and diagnostic tools for use by Indigenous organisations and communities and agencies working with them. The project also aims to make the research count 
with governments. For that purpose, various policy, funding and program frameworks have been analysed and reported on.

The research is now starting to tell us about what works, what doesn't and why in Indigenous community governance in Australia. In particular, the evidence is consistently highlighting several conclusions that are directly relevant to the Federal Government's new intervention policy.

\section{Project research implications for the new intervention policy}

The ICG Project has thoroughly investigated and analysed the factors underlying poor governance arrangements in Indigenous communities. These are discussed in reports and case studies on the CAEPR web site. Given the current government and public focus on Indigenous dysfunction and failure, however, it is important to remember that Indigenous communities can be successful in establishing good governance and that in doing so they are securing important social, cultural and economic outcomes.

\section{What is working}

First, the research overwhelmingly confirms that the exercise of practically effective, culturally legitimate governance in Indigenous communities is critical to providing a foundation for addressing and sustaining their social wellbeing and economic development. In other words, good governance delivers a development dividend for Indigenous communities.

Second, lest we all succumb to the politics of despair about Indigenous Australia that seems to have hold of the nation at the moment, the research reports that amid the failures there are extraordinary successes in community governance.

Around the country, we are seeing Indigenous people in their organisations and communities working to address complex internal relationships and representation issues in order to develop legitimate governing arrangements that win the support of their members (for example, the West Arnhem Land Transitional Committee is developing an innovative organisational structure with a layered network of representation that will enable it to act regionally, but also recognise local community interests and decision making [Smith 2007]).

We are documenting Indigenous groups reassessing their cultural histories and geographies in order to promote greater legitimacy and accountability of leadership and decision making (for example, groups at Wadeye in the Northern Territory undertook an extensive community-wide reappraisal of the cultural underpinnings of their governance arrangements in order to create a more inclusive community council).

Project researchers have reported innovative governing structures being designed to suit changing contemporary conditions (for example, the Layhnapuy Resource Association represents the interests of a number of interrelated outstations across 
East Arnhem Land and has recently restructured its governing board and management in order to better respond to changing government policy and economic opportunities for its member groups).

We are seeing direct links between the effectiveness of an organisation's governance arrangements and its ability to deliver sustained social and economic development outcomes (for example, Yarnteen Corporation in Newcastle has built up an outstanding governing board and management team who promote continuing governance training, professional development and youth mentoring. This has led to high credibility with the wider business community and investors, and has resulted in sustained success in enterprise development).

The ICG Project's research is also identifying a set of core 'design principles' that appears to underlie many of the different governance solutions on the ground. A particularly important principle is networked governance, which is applicable in remote, rural and urban communities. It is premised on a form of 'bottom-up' federalism with associated layers of power, roles and responsibilities (for example, the set of organisations and interrelated groups that now constitutes the Bunaba Corporation is a network designed to recognise the autonomy of particular groups and their economic interests, at the same time as sharing the benefits of collective representation and financial management). Models based on networked governance are seen in all the communities with which project's researchers are working.

Strong nodal leadership and succession planning are shown to make a significant contribution to the good governance of communities and organisations. Influential leaders become connecting points within networks to mobilise resources and opinions and get things done. Under their direction, the project has documented organisations undertaking the hard work of reforming their governance, creating workable rules and procedures and enforcing those in the complex inter-cultural environments in which they operate.

In particular, the research has documented innovative Indigenous processes of building practical governance capacity in the context of their daily work. When Indigenous people develop their own institutions rather than adopt externally created rules, their governance capacity and confidence appear to be significantly strengthened. In all the case studies, we are witnessing community groups and leaders using their cultural values and social relationships as assets to help them build stronger governance.

\section{What isn't working}

Many of the intractable social and economic problems confronting Indigenous Australians are, in significant part, a function of the mutually reinforcing institutional constraints and failure of governance within governments themselves. The ICG Project has documented institutional failings in policy, 
implementation strategies, funding frameworks, public-sector capacity and the system of fiscal federalism itself (see Westbury and Dillon 2006).

The way governments function directly affects Indigenous capacity to govern well and get things done in communities. In every case study, researchers are reporting that there is no single, whole-of-government policy approach; rather, there are several. Organisations and communities are routinely confronted with different whole-of-government policies and strategies from different departments and jurisdictions.

Departmental territorialism and inertia is rampant in Indigenous affairs. We have witnessed Indigenous initiatives to improve local governance undermined by the 'go-it-alone' attitude of particularly influential departments, which protect their niche program role and funding power and resist the efforts of other agencies to collaboratively develop program and funding coordination. The point was highlighted at one COAG trial meeting by a perceptive community leader, who asked the various departmental officers the question: 'Where is your thamarrurr?' He was one of the local leaders involved in the time-consuming, difficult task of getting the different clans to work together under a single regional council modelled on a traditional principle of thamarrurr ('coming together'). Why, he asked, couldn't governments work with each other, and why couldn't they get their departments to work together?

What hasn't been recognised - at least by governments - but what has been documented by the ICG Project and numerous reports and inquiries, is the extent to which government funding arrangements have exacerbated community and organisational dysfunction and poor governance. As Westbury and Dillon (2006) succinctly note, for Indigenous communities, 'accessing government program resources becomes a labyrinthine voyage through scores of separate programs and a sea of bureaucratic process'. This fundamentally diminishes the time, resources and capacity that community organisations can give to making their service delivery and governance more effective.

Government policy in the past 30 years has not succeeded in addressing this internal institutional failure. On the contrary, programs seem to be multiplying and grant funding and acquittal processes are becoming more onerous. In one community, at the time it began participating in a COAG trial, its representative organisation was managing 50 different buckets of government program funding. For a small community of approximately 2300 people, that in itself constituted a major administrative workload that diverted scarce human resources away from critical community governance and service issues. After three years of the trial, the same organisation was managing more than 90 different buckets of program money.

There continues to be, in Indigenous affairs, a fundamental disjunction between government policy goals and real implementation on the ground. This is 
compounded by a failure of engagement by governments at all levels. When governments introduced self-determination policies in the 1970s, they essentially vacated the field of community development and collaborative engagement on the ground. The result was a failure to keep up with international best practice in community development, which might have enabled a more sophisticated approach to the issues involved in the current intervention. The additional consequence has been a failure of governance capacity within an already overstretched bureaucracy reeling from one policy change after another.

A plethora of papers and reports has concluded that the institutional arrangements of fiscal federalism in Australia are fundamentally flawed and a key driver of Indigenous disadvantage, especially in remote regions. For example, the per capita allocation from Commonwealth transfers to local government in the Northern Territory makes up just more than $\$ 20$ million of a $\$ 1$ billion national pool of specific-purpose grants. The bizarre result is that the Northern Territory receives less in local government financial assistance than is notionally allocated for the population of Geelong in Victoria (Westbury and Dillon 2006).

The result in the Northern Territory, which covers more than one-sixth of the Australian landmass and has an Indigenous population experiencing high levels of socioeconomic disadvantage, has been to create huge backlogs in infrastructure and services in local communities. These are the very communities now being accused of not delivering much-needed basic services to children and families.

Infrastructure backlogs are not currently addressed by the Commonwealth Grants Commission (CGC), and the jurisdictional sovereignty of territory and state governments means they are not required to expend Commonwealth transfers on the Indigenous locations or service requirements against which 'disability factors' the transfers were initially assessed by the CGC (Smith 1992). As a result of the historical under-investment by governments in NT communities, CAEPR has recently estimated that to deliver on its intervention promise to spend whatever it takes to 'fix up' Indigenous communities in the Northern Territory, the Federal Government will need to allocate in the realm of $\$ 3-5$ billion to achieve parity in the next five years in education, health, Community Development Employment Projects (CDEP) program transitions to work and housing alone.

We have entered a period of policy formulation in which Indigenous culture is pathologised by governments and many public commentators in much the same way as early missionaries regarded Indigenous culture as contaminating the ability of families and children to assimilate. Indigenous culture is portrayed almost as a virus, something that will undermine the effectiveness and accountability of organisations and their governance arrangements. Accordingly, policy and program solutions increasingly seek to quarantine culture to one side. The primary mode of departmental interaction with community 
organisations is one of managerial governance that focuses on compliance and grant acquittal. The lesson of history, however, is that Indigenous people will never leave their culture to one side; they will not be assimilated into being 'whitefellas' and their governance arrangements express cultural goals in addition to financial compliance and administrative effectiveness. Importantly, the ICG Project has documented examples of where Indigenous groups and organisations are using their cultural values, institutions and social relationships to positively support their collective efforts to rebuild their governing arrangements. In other words, cultural legitimacy can provide a powerful mechanism for accountability and effectiveness.

By and large, however, governments still do not recognise the positive developmental role of good governance, and their efforts to facilitate Indigenous governance capacity building at the local level remain ad hoc, uncoordinated, erratically funded, poorly implemented and are rarely followed up. The recommendations of numerous reports and inquiries on community governance and associated capacity building have not been implemented.

Taken together, these issues produce what Westbury and Dillon (2006) conclude is 'a fundamental failure of the nation state to govern effectively in Indigenous Affairs'. It also represents a fundamental failure of the Australian State to invest in Indigenous self-governance and related capacity, despite the mounting evidence that this can lead to significantly improved social and economic outcomes on the ground.

In many ways, an inevitable conclusion must be that the governance dysfunction within government represents at least half of the national emergency currently confronting Indigenous communities.

\section{From coercion to collaboration?}

Coercion as a policy instrument has limited developmental power for Indigenous families and communities; history has demonstrated that. Government ministers and bureaucrats often talk about the importance of developing policies and strategies on evidence-based research. The ICG Project is producing convincing comparative evidence that suggests that there are several strategies that will facilitate more effective, sustained outcomes.

First, taking genuine decision-making powers and control away from communities and organisations, and then handing them back later and expecting Indigenous people to assume 'ownership' of models and rules they have had no say in developing, will not work. In this respect at least, the ICG Project's research suggests that Noel Pearson is wrong. He has argued (Pearson 2007) that there are three policy phases to the Federal Government's decisive action: the first is unilateral intervention on the ground; the second is radical reform and 
innovation; the third is retreat by government and transfer of ownership to Indigenous organisations and leaders.

In fact, Indigenous self-governance and good governance lie at the very heart of positive development outcomes. Governments urgently need to provide enabling policy and legal frameworks, and integrated program guidelines, to actively promote Indigenous governance capacity and authority. Building Indigenous governance institutions and capacity should be built into any new interventions - right from the start.

Governments also need to urgently put some implementation backbone into the policy rhetoric of 'whole of government', especially in relation to funding. At the macro level, fundamental reforms to federal fiscal institutions need to be made, as they affect funding transfers to and expenditure by state and territory governments on services and programs for Indigenous people. These transfers must be allocated to the areas of substantial community need, on the bases of which they were initially determined by the CGC. Associated infrastructure/capital backlogs and cost shifting by governments to Indigenous local governments and small community organisations must be addressed at policy and institutional levels within government. Also, the CGC should be requested to include a new category that assesses Indigenous community infrastructure/capital needs (Westbury and Dillon 2006).

If we can have decisive action in Indigenous communities, presumably the same is possible within government. At a micro level, there is arguably an urgent need for the mandatory integration of program funding across departments that is relevant to community governance and capacity building. The stories presented at the beginning of this chapter and the case-study evidence of the ICG Project indicate that there are communities, organisations and leaders who want decisive action from government, but in partnership and with reform on both sides.

In conclusion, our case-study research clearly demonstrates that building governance institutions and capacity needs to be placed at the forefront of any proposed intervention from the very start, not as an afterthought. 'Governance building' should be made an integral part of every policy and its implementation on the ground. Simultaneously, the reform of governments' own governance dysfunction and bureaucratic capacity in Indigenous affairs has to be a fundamental component of any solution. Without these two parallel strategies, it is likely that the current 'decisive action' will exacerbate problems, not alleviate them.

Readers can access the CAEPR web site at <http://www.anu.edu.au/caepr/> 


\section{References}

Adlam, N. and Gartrell, A. 2007, 'Martial law-Howard mobilises cops, military as he declares "national emergency" in NT communities', NT News, Friday 22 June 2007, Darwin, Northern Territory.

Evans, L., Appo, H. and Smith, D. E. 2006, Community development practices and principles in the development of the West Central Arnhem Regional Authority, Unpublished discussion paper, Department of Local Government, Housing and Sport, Darwin, Northern Territory.

Hunt, J. and Smith, D. E. 2006, The Indigenous Community Governance Project. Preliminary research findings, CAEPR Working Paper 31, Centre for Aboriginal Economic Policy Research, The Australian National University, Canberra.

Hunt, J. and Smith, D. E. 2007, The Indigenous Community Governance Project. Phase two research findings, CAEPR Working Paper 36, Centre for Aboriginal Economic Policy Research, The Australian National University, Canberra.

Ngaanyatjarra, Pitjantjatjara Yankunytjatjara Women's Council 1991, Looking after children grandmothers' way, Unpublished report to the Child Protection Policy and Planning Unit, Government of South Australia, Adelaide.

Pearson, N. 2007, 'Three phases of the rescue operation', The Weekend Australian, 23-24 June 2007, p. 22.

Scott, J. C. 1998, Seeing Like a State: How certain schemes to improve the human condition have failed, Yale University Press, New Haven.

Smith, D. E. 1992, An analysis of the Aboriginal component of Commonwealth fiscal flows to the Northern Territory, CAEPR Discussion Paper 29, Centre for Aboriginal Economic Policy Research, The Australian National University, Canberra.

Smith, D. E. 2001, Community Participation Agreements: a model for welfare reform from community-based research, CAEPR Discussion Paper 223, Centre for Aboriginal Economic Policy Research, The Australian National University, Canberra.

Smith, D. E. 2005, Researching Australian Indigenous governance: a methodological and conceptual framework, CAEPR Working Paper 29, Centre for Aboriginal Economic Policy Research, The Australian National University, Canberra.

Smith D. E. 2007, 'Networked governance: issues of process, policy and power in a West Arnhem Land regional initiative', Ngyia Talk the Law, Journal of the Jumbunna Centre, University of Technology, Sydney. 
Westbury, N. and Dillon, M. 2006, The institutional underpinnings of Indigenous disadvantage: the failed state within, Unpublished paper, Canberra.

\section{ENDNOTES}

${ }^{1}$ For more information on the bilateral agreement, the process and history of the NT local government regionalisation in West Arnhem Land, see Smith $(2005,2007)$. 